\title{
DESAIN PENGEMBANGAN KURIKULUM PRODI TEOLOGI FAKULTAS ILMU TEOLOGI IAKN TARUTUNG UNTUK MENGHASILKAN LULUSAN YANG TERAMPIL MENGAJAR
}

\author{
Iwan Setiawan Tarigan, Bernhardt Siburian, Arip Surpi Sitompul, Nurelni \\ Limbong, Megawati Manullang \\ Institut Agama Kristen Negeri (IAKN) Tarutung, Indonesia \\ Email: iwanstarigan@gmail.com, siburian.bernhardt@gmail.com, \\ aripsurpisitompul@gmail.com, limbongnurelni01@gmail.com, \\ megamanullang2@gmail.com
}

\begin{abstract}
Abstrak
Penelitian ini bertujuan untuk menghasilkan desain kurikulum yang dikembangkan dari kurikulum Prodi Teologi IAKN Tarutung yang saat ini sedang digunakan sebagai usul kepada pimpinan institusi untuk menghasilkan lulusan yang terampil mengajar. Data primer penelitian ini diperoleh dari jawaban pertanyaan wawancara terhadap enam pemimpin gereja lokal (Pendeta Ressort) dan yang menjadi populasi dan sampel sekunder adalah kurikulum Prodi Teologi Tahun 2021 yang sedang digunakan pada saat ini. Penelitian ini menggunakan pendekatan kualitatif deskriptif dengan metode wawancara terstruktur tentang keterampilan mengajar mahasiswa Prodi Teologi IAKN Tarutung tahun 2021 dan juga kajian teoritis terhadap kurikulum Prodi Teologi Tahun 2021 yang sedang digunakan pada saat ini. Hasil analisa jawaban responden menunjukkan bahwa indeks keterampilan mengajar mahasiswa berada pada angka 59,46\%, yaitu pada level 55 - $64 \%$ atau pada kualifikasi 'kurang terampil'. Berdasarkan hasil analisa jawaban responden yang menunjukkan titik lemah keterampilan mengajar mahasiswa diperhadapkan dengan analisis reflektif susunan kurikulum Prodi Teologi IAKN Tarutung, tim peneliti mengusulkan penambahan matakuliah Didaktik Metodik Teologi, Evaluasi Pembelajaran Teologi, Microteaching Teologi sebagai jawaban pertama masalah penelitian ini. Sedangkan jawaban kedua masalah penelitian ini menunjukkan bahwa hasil rata-rata penilaian validator terhadap pengembangan kurikulum berupa penambahan ketiga matakuliah tersebut berada pada angka adalah 65,6 \%, yaitu berada pada level tingkat ketercapaian $65 \% \square 74 \%$, masuk dalam kualifikasi cukup layak, dengan revisi pada bagian-bagian tertentu yang ditunjuk. Berdasarkan hasil analisa tersebut maka diberikan rekomendasi bahwa Prodi Teologi IAKN tetap konsisten pada visi dan misinya, secara team-teaching, tetap menjadi penyelenggara ketiga penambahan matakuliah tersebut sebagai hasil desain pengembangan kurikulum.
\end{abstract}

Kata Kunci: pengembangan; kurikulum; terampil; mengajar

$\begin{array}{lllll}\text { How to cite: } & \text { Tarigan. I.S., Bernhardt Siburian, Arip Surpi Sitompul, Nurelni Limbong \& Megawati Manullang (2021) } \\ & \text { Desain Pengembangan Kurikulum Prodi Teologi Fakultas Ilmu Teologi Iakn Tarutung Untuk Menghasilkan } \\ & \text { Lulusan Yang Terampil Mengajar. Syntax Literate: Jurnal Ilmiah Indonesia, } 6(12) .\end{array}$


Iwan Setiawan Tarigan, Bernhardt Siburian, Arip Surpi Sitompul, Nurelni Limbong, Megawati Manullang

\section{Abstract}

This study aims to arrange a curriculum design developed from the curriculum of the Theology Study Program at IAKN Tarutung which is currently being used as a proposal to institutional leaders to produce graduates who are skilled in teaching. The primary data of this study was obtained from the answers to interview questions of six local church leaders (Ressort Pastors) and the population and the secondary sample was the 2021 Theology Study Program curriculum which is currently being used. This study uses a descriptive qualitative approach with a structured interview method about the teaching skills of the 2021 IAKN Tarutung Theology Study Program students and also a theoretical study of the 2021 Theology Study Program curriculum that is currently being used. The results of the analysis of respondents' answers show that the index of student teaching skills is at $59.46 \%$, namely at the level of $55-64 \%$ or in the 'less skilled' qualification. Based on the results of the analysis of respondents' answers which showed the weak points of students' teaching skills faced with a reflective analysis of the curriculum structure of the Tarutung IAKN Theology Study Program, the research team proposed adding the Theology Methodology Didactic, Theology Learning Evaluation, Theology Microteaching courses as the first answer to this research problem. While the answers to the two research problems indicate that the average result of the validator's assessment of curriculum development in the form of adding the three courses is 65.6\%, which is at the level of achievement level of $65 \% 74 \%$, entering the qualifications quite decent, with revision of certain designated sections. Based on the results of the analysis, a recommendation is given that the IAKN Theology Study Program remains consistent in its vision and mission, in a team-teaching manner, remains the organizer of the three additional courses as a result of the curriculum development design.

Keywords: development; curriculum; skilled; teaching

Received: 2021-11-20; Accepted: 2021-12-05; Published: 2021-12-20

\section{Pendahuluan}

Dalam percakapan informal para dosen dengan beberapa lulusan Prodi Teologi IAKN Tarutung yang mengajukan lamaran dan diterima di berbagai lapangan pekerjaan agaknya mereka membutuhkan keterampilan tambahan dalam dunia kerja mereka yaitu keterampilan dasar mengajar (Sukirman, 2010). Selain unsur pengajaran dalam penata layanan di gereja, keterampilan dasar mengajar juga sangat dibutuhkan gereja, khususnya gereja-gereja yang memiliki lembaga pendidikan formal.

Oleh sebab itu tim peneliti mengamati kurikulum yang sudah diterapkan ternyata ada beberapa mata kuliah yang perlu dikembangkaan yang memampukan para lulusan menjadi pengajar dengan mata kuliah yang dapat mewujudkan visi dan misi Prodi Teologi IAKN Tarutung serta sesuai dengan kompetensi pendukung lulusan yakni kemampuan melayani, menggembalakan, mengajar di lembaga pemerintahan, gereja dan swasta. Situasi inilah yang mendorong tim peneliti melakukan kajian kurikulum Prodi Teologi IAKN Tarutung (Hamalik, 2007). 


\section{Metode Penelitian}

Metode yang digunakan dalam penelitian ini adalah kualitatif deskriptif (Sugiyono, 2017). Penelitian ini berupaya memberikan gambaran dengan menggunakan kata-kata dan angka atau menyajikan profil persoalan, klasifikasi, jenis atau garis besar tahapan-tahapan guna menjawab masalah penelitian untuk menghasilkan desain pengembangan kurikulum Prodi Teologi Fakultas Ilmu Teologi Institut Agama Kristen Negeri (IAKN) Tarutung (Hamzah, 2019).

Oleh sebab fokus utama masalah penelitian ini adalah keterampilan dasar mengajar (kompetensi dasar pedagogik), tujuh aspek kompetensi yang terdapat dalam Pasal 10 UU No. 14 Tahun 2005 tentang Guru dan Dosen dan juga keterampilan dasar mengajar menurut (Ifrianti, 2018) yang akan menjadi dasar pertimbangan bagi tim peneliti untuk mengembangkan kurikulum Prodi Teologi sebagai acuan dalam menjawab masalah penelitian ini.

\section{Hasil dan Pembahasan}

\section{A. Analisa Pendahuluan}

Berdasarkan potensi dan masalah penelitian ini dapat diketahui bahwa dugaan tentang kurang memadainya keterampilan mahasiswa dalam mengajar agaknya sesuai dengan keadaan yang peneliti kompilasi melalui jawaban para responden pada penelitian pendahuluan (lihat Lampiran 1). Umumnya para informan (pengguna) menginformasikan hal serupa. Dari hasil pengolahan data secara sederhana dengan rumus rata-rata persentase, dapat diketahui bahwa keterampilan para mahasiswa dalam mengajar berada pada angka 59,46 \%. Data awal penelitian pendahuuan ini menunjukkan bahwa situasi keterampilan mengajar mahasiswa berada pada level 55 - $64 \%$, yaitu pada kualifikasi 'kurang terampil', sebagaimana dipaparkan pada diagram berikut.

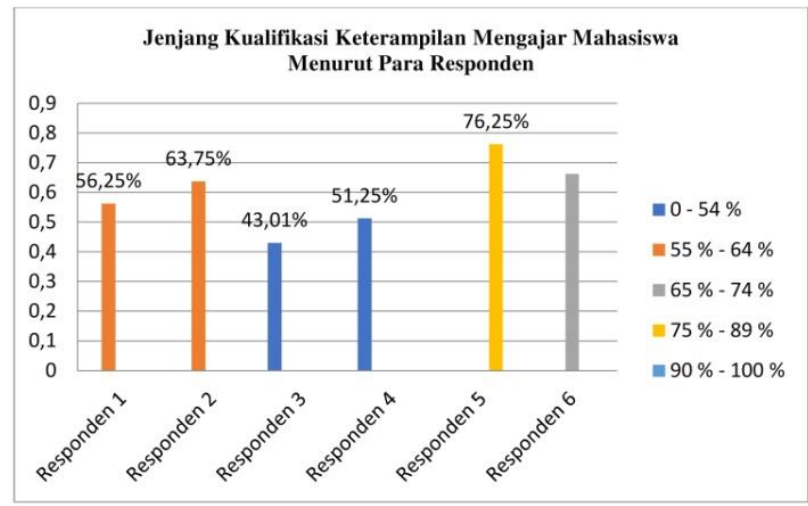

Gambar 1

Jenjang Kualifikasi Keterampilan Menagajar Mahasiswa 
Iwan Setiawan Tarigan, Bernhardt Siburian, Arip Surpi Sitompul, Nurelni Limbong, Megawati Manullang

Berdasarkan hasil pengolahan data tersebut maka penelitian ini dapat diteruskan kepada tahap selanjutnya, yaitu perencanaan dan pengembangan kurikulum (Hamalik, 2006).

Dalam Kurikulum Prodi Teologi yang telah dan sedang digunakan hingga saat ini (Tahun Akademik 2021/2022) peneliti mengamati bahwa cukup besar peluang dan sangat memungkinkan melakukan penambahan dan atau pengayaan matakuliahmatakuliah metode pendidikan (Didaktik Metodik) dalam susunan kurikulum Prodi Teologi IAKN Tarutung. Sekalipun Kurikulum Merdeka Belajar - Kampus Merdeka sudah diberlakukan sejak 24 Januari 2020, peluang penambahan matakuliahmatakuliah tersebut masih dapat dan sangat mungkin dilakukan. Apalagi kebijakan tersebut dilatarbelakangi oleh tuntutan arus perubahan dan kebutuhan akan link and match dunia kampus dengan dunia kerja (usaha atau industri) bahwa dalam hal ini keterampilan mengajar mahasiswa (yang mengikuti program Magang dan PPLKKN) dan lulusan Prodi Teologi IAKN Tarutung juga sangat dibutuhkan di dunia pelayanan gereja.

\section{B. Hasil dan Interpretasi}

Berdasarkan desain pengembangan kurikulum Prodi Teologi di atas, peneliti mengusulkan untuk menambah tiga matakuliah baru sebagai jawaban rumusan masalah penelitian ini, yaitu Didaktik Metodik Teologi (sebagai pengganti Matakuliah Pilihan I yang diselenggarakan pada pada Semester IV), Evaluasi Pembelajaran Teologi (sebagai pengganti Matakuliah Pilihan II pada Semester V) dan Microteaching Teologi (sebagai pengganti Matakuliah Pilihan III pada Semester VI) sebagai analisis refleksi titik lemah keterampilan mengajar (kompetensi pedagogik) para mahasiswa Prodi Teologi IAKN Tarutung. Alasannya adalah bahwa ketiga matakuliah tersebut, melalui deskripsi dan silabus masing-masing, dapat meningkatkan keterampilan mengajar mahasiswa Prodi Teologi IAKN Tarutung sebagaimana yang diharapkan oleh para pengguna mahasiswa (Pendeta Ressort).

Penentuan ketiga matakuliah tersebut didasarkan pada analisa deskriptif sederhana dan juga analisa reflektif terhadap titik lemah keterampilan mengajar mahasiswa atas penilaian para Pendeta Ressort diperhadapkan dengan tujuh aspek kompetensi yang terdapat dalam Pasal 10 UU No. 14 Tahun 2005 dan juga keterampilan dasar mengajar menurut (Ifrianti, 2018). Dengan demikian ketiga matakuliah tersebut merupakan matakuliah dasar dan standar wajib diselenggarakan oleh Prodi Teologi IAKN Tarutung untuk meningkatkan keterampilan mengajar (kompetensi pedagogik) bagi para mahasiswa.

Para peneliti juga telah menyusun deskripsi ketiga matakuliah-matakuliah pengembangan tersebut sedemikian rupa sebagai bagian integral dari pengembangan kurikulum tersebut (Miller \& Seller, 1985). Ketiga Deskripsi Matakuliah tersebut kemudian dikembangkan lagi menjadi Silabus Matakuliah sebagai hasil pengumpulan dan analisis data melalui pembacaan efektif sumber-sumber litaeratur 
koheren. Dengan demikian matakuliah-matakuliah yang awalnya bersifat pilihan, kini telah berubah menjadi matakuliah-matakuliah wajib.

Setelah Deskripsi Matakuliah dan Silabus selesai disusun, peneliti menyusun lembar validasi para ahli untuk menilai kelayakan ketiga matakuliah tersebut menjadi konsep desain pengembangan kurikulum Prodi Teologi IAKN Tarutung.

\section{Validasi Ahli}

Berdasarkan perolehan data sekunder dapat diketahui bahwa skor masingmasing item penilaian seluruh validator memiliki selisih yang tidak begitu besar, yaitu pada skor 12, 13, 14 dan 15 . Skor paling rendah ada pada item penilaian nomor 2, 3, 4 dan 5, yaitu pada angka 12; sedangkan yang paling tinggi adalah item nomor 7 dan 13, yaitu pada angka 15. Tetapi dari segi jumlah, total penilaian masing-masing validator agak bervariasi.

Item penilaian nomor 2, 3, 4 dan 5 adalah mengenai pengadaan atau penambahan matakuliah Didaktik Metodik Teologi (Surabaya, 1989). Para validator di bidang pendidikan memberikan kritik dan saran mengenai matakuliah ini, yang akan peneliti kritisi kemudian. Sedangkan item nomor 7 dan 13 adalah mengenai penilaian pengadaan atau penambahan matakuliah Evaluasi Pembelajaran Teologi dan matakuliah Microteaching Teologi (Yulianto \& Hutasoit, 2020), bahwa kedua matakuliah tersebut sudah tepat diadakan dan atau ditambahkan pada pengembangan kurikulum.

Persentase rata-rata hasil penilaian validator di bidang Kurikulum Pendidikan adalah 46,5\% (Pidarta, 1997). Persentase rata-rata hasil penilaian validator di bidang Umum adalah $75 \%$. Persentase rata-rata hasil penilaian validator di bidang Teologi adalah $80 \%$. Dan persentase rata-rata hasil penilaian validator di ketiga bidang tersebut adalah 65,6 \%. Hasil penilaian ini masuk ke dalam tingkat Kualifikasi cukup layak (Tingkat Ketercapaian $65 \%-74 \%$ ) dengan revisi pada bagian-bagian tertentu yang ditunjuk, sebagaimana diagram berikut:

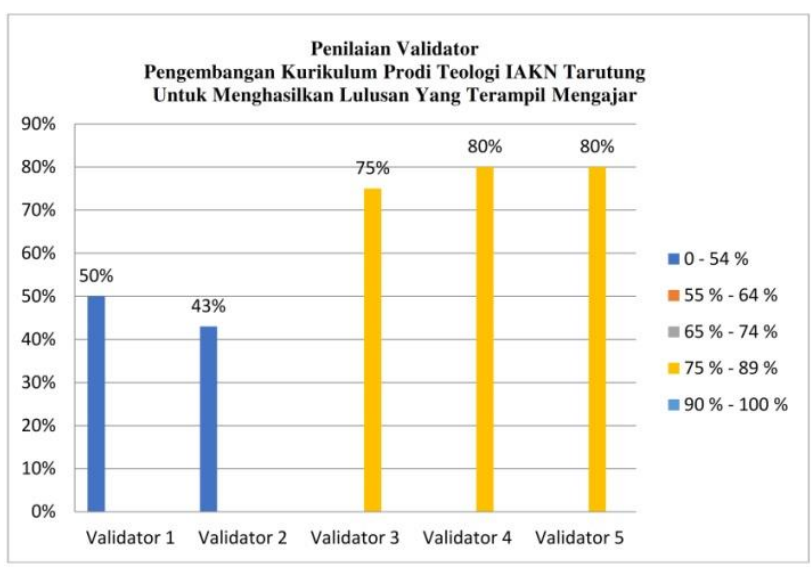

Gambar 2 Penilaian Validator 
Iwan Setiawan Tarigan, Bernhardt Siburian, Arip Surpi Sitompul, Nurelni Limbong, Megawati Manullang

Berdasarkan uraian di atas dapat disimpulkan bahwa Pengembangan Kurikulum Berbasis KKNI dan Merdeka Belajar- Kampus Merdeka pada Program Studi Teologi Fakultas Ilmu Teologi IAKN Tarutung yang dikembangkan pada penelitian ini cukup layak untuk digunakan dalam menghasilkan lulusan yang terampil mengajar (Sanjaya, 2008).

Persentase rata-rata hasil penilaian validator di bidang Kurikulum Pendidikan adalah 46,5 \%. Para validator di bidang pendidikan mengungkapkan bahwa lulusan Prodi Teologi tidak sebaiknya berorientasi di bidang pendidikan. Bila hal itu tetap dilakukan, selain tiga matakuliah yang telah diajukan, desain kurikulum Prodi Teologi tersebut sebaiknya ditambahkan lagi dengan beberapa matakuliahmatakuliah pendidikan lainnya, secara khusus mengenai : Pengantar Pendidikan Kristen, Landasan Pendidikan Kristen, Jalur Jenjang Jenis Bentuk Pendidikan Kristen, Kurikulum Gereja, Pendidikan Anak di Gereja, Pendidikan Remaja dan Pemuda di Gereja, Pendidikan Kaum Dewasa di Gereja. Oleh sebab ketiadaan matakuliah-matakuliah ini, validator merasakan bahwa pengembangan desain kurikulum tersebut belum memadai. Namun demikian para validator bidang pendidikan dapat memahami tuntutan situasi dalam penelitian dan keadaan lulusan yang diharapkan dapat juga terampil mengajar. Paling tidak, lulusan Prodi Teologi IAKN dapat mempersiapkan diri atau menerapkan keterampilan mengajar pada institusi pendidikan formal gereja (SD, SMP, SMA dan Perguruan Tinggi yang dikelola dan atau milik gereja).

Sebagaimana telah diutarakan di tas bahwa hasil penilaian ini masuk ke dalam tingkat kualifikasi cukup layak (tingkat ketercapaian $65 \%-74 \%$ ) dengan revisi pada bagian-bagian tertentu yang ditunjuk, item perbaikan yang dimaksud dalam usulan validator di bidang kurikulum/pendidikan adalah bukan pada konten silabus atau deskripsi matakuliah yang memiliki skor rendah, melainkan pada penambahan matakuliah-matakuliah pendidikan lainnya dalam pemenuhan jawaban masalah penelitian ini sebagainana yang telah dilaksanakan pada Prodi PAK IAKN Tarutung.

Pada bagian kritik dan saran lembar penilaian validasi ahli, para validator Bidang Kurikulum Pendidikan agaknya kurang menyetujui visi dan misi Prodi Teologi orientasinya diarahkan kepada keterampilan mengajar. Pertimbangan para validator adalah bahwa kualifikasi terampil mengajar sudah terdapat pada Prodi Pendidikan Agama Kristen (PAK), bahwa keterampilan mengajar bukanlah keahlian Sarjana Teologi. Validator menghendaki agar visi dan misi Prodi Teologi tidak 'melenceng' dari yang sudah ditetapkan semula. Mereka juga mengusulkan apabila gereja (pengguna lulusan) membutuhkan lulusan yang terampil mengajar, ada baiknya gereja perlu menyusun kurikulum pelayanannya pada ranah anak-anak, remaja/pemuda dan untuk dewasa/orangtua. Selain ketiga matakuliah-matakuliah pengembangan disebut di atas, para validator juga mengusulkan agar matakuliah : Pengantar Pendidikan Kristen, Landasan Pendidikan Kristen, Jalur, Jenjang, Jenis 
dan Bentuk Pendidikan Kristen, Desain Kurikulum Gereja perlu diadakan pada Prodi Teologi, tanpa harus menghilangkan ciri utama visi dan misi Prodi Teologi.

Di sisi lain, para validator Bidang Teologi menyarankan agar ketiga matakuliah bidang pendidikan dapat saja ditambahkan untuk pemenuhan visi dan misi Prodi Teologi IAKN dalam menciptakan lulusan yang terampil mengajar. Namun demikian ada beberapa hal yang perlu diperhatikan sehubungan dengan program Merdeka Belajar - Kampus Merdeka dan juga Visi dan Misi Program Studi Teologi IAKN Tarutung. Matakuliah-matakuliah hasil pengembangan tersebut tetap perlu dimunculkan dalam susunan dan hirarki kurikulum Prodi Teologi. Namun pelaksanaannya dilakukan dengan cara team-teaching. Apabila institusi pengguna lulusan membutuhkan keterampilan mengajar, mahasiswa Prodi Teologi dapat saja mengambil SKS matakuliah-matakuliah pendidikan tersebut di luar kampus atau di luar prodi-nya sesuai dengan Peraturan Menteri Pendidikan dan Kebudayaan RI. Artinya, mahasiswa dapat mengambil SKS matakuliah-matakuliah pendidikan tersebut sebagai matakuliah pilihan atas kemauannya sendiri.

Yang berikut, apabila Program Studi Teologi memang sudah melakukan analisis kebutuhan pengguna lulusan sedemikian rupa, Prodi dapat merumuskan Visi dan Misi-nya dengan mencantumkan Keterampilan Mengajar sebagai salah satu pokok penting dalam proses pembelajaran di lingkungan Program Studi Teologi IAKN Tarutung.

Sehubungan dengan program Menteri pendidikan dan Kebudayaan tentang Merdeka Belajar - Kampus Merdeka, Permendikbud No. 3 Tahun 2020, tentang Standar Nasional Pendidikan Tinggi, tertulis bahwa Perguruan Tinggi wajib memberikan hak bagi mahasiswa untuk secara sukarela mengambil ataupun tidak Perguruan Tinggi wajib memfasilitasi hak bagi mahasiswa untuk mengambil SKS di luar Perguruan Tinggi-nya selama 2 semester (setara dengan 40 SKS) dan atau mengambil SKS di luar Program Studi-nya Perguruan Tingginya selama 1 semester (setara dengan $20 \mathrm{SKS}$ ). Oleh program ini ketiga matakuliah pendidikan yang menjadi hasil analisis pengambangan kurikulum Prodi Teologi dapat saja ditambahkan demi pemenuhan visi dan misi Prodi dalam menciptakan lulusan yang terampil mengajar. Program ini memberi suasana merdeka bagi mahasiswa Prodi Teologi untuk mengambil SKS matakuliah pendidikan tersebut pada Prodi lain di luar Prodi-nya.

Dalam lingkungan IAKN Tarutung, Prodi yang dapat dituju untuk mengambil SKS matakuliah pendidikan tersebut ada pada Prodi Pendidikan Agama Kristen (PAK). Selain wajib memfasilitasi para mahasiswa dalam pemenuhan program Merdeka Belajar - Kampus Merdeka, IAKN juga perlu membentuk Team Teaching dalam pelaksanaan pembelajaram matakuliah pendidikan tersebut agar kolaborasi antara bidang Teologi dan Pendidikan dapat diterapkan pada matakuliah-matakuliah pengembangan tersebut.

Situasi ini tentu saja tidak serta-merta membelenggu para mahasiswa Prodi Teologi IAKN dalam mengkontrak matakuliah-matakuliah pilihan yang tersedia. 
Iwan Setiawan Tarigan, Bernhardt Siburian, Arip Surpi Sitompul, Nurelni Limbong, Megawati Manullang

Peneliti memberikan pertimbangan bahwa matakuliah-matakuliah pilihan tersebut dapat dikontrak oleh mahasiswa dengan prasyarat-prasyarat tertentu yang ditetapkan oleh Prodi Teologi, misalnya dengan asumsi beban 0 SKS bagi mahasiswa dan standar SKS tertentu bagi Dosen Pengampu matakuliah-matakuliah pilihan.

Selain dengan melakukan penambahan ketiga matakuliah tersebut diharapkan bahwa baik mahasiswa yang akan menjalani program PPL dan KKN serta dan para alumni dalam lingkup dunia kerja pengguna lulusan dapat menghasilkan kemampuan mengajar yang terampil. Tidak hanya oleh unsur ketiga matakuliah sebagai pengembangan kurikulum secara tersendiri tetapi sekuense dan rangkaian matakuliah-matakuliah dalam kurikulum pengembangan tersebut dalam tiap semester dapat menopang dalam menghasilkan mahasiswa dan lulusan Prodi Teologi Fakultas Ilmu Teologi IAKN yang terampil mengajar.

\section{Kesimpulan}

Dari hasil penelitian ini, tim peneliti merumuskan kesimpulan sebagai berikut: 1). Pengembangan kurikulum Prodi Teologi yang dihasilkan melalui penelitian ini adalah penambahan tiga matakuliah baru, yaitu : Didaktik Metodik Teologi, Evaluasi Pembelajaran Teologi dan Microteaching Teologi beserta dengan silabus dan deskripsi matakuliah tersebut. 2). Secara umum, berdasarkan hasil pengolahan data validasi pengembangan kurikulum Prodi Teologi IAKN Tarutung menunjukkan bahwa desain pengembangan kurikulum Prodi Teologi IAKN Tarutung adalah dengan kualifikasi cukup layak yaitu berada pada tingkat ketercapaian $65 \%-74 \%$, dengan revisi pada bagian-bagian tertentu yang ditunjuk. 3). Item perbaikan yang dimaksud dalam usulan validator di bidang kurikulum/pendidikan adalah bukan pada konten silabus atau deskripsi matakuliah yang memiliki skor rendah, melainkan pada penambahan matakuliah-matakuliah pendidikan lainnya dalam pemenuhan jawaban masalah penelitian ini sebagainana yang telah dilaksanakan pada Prodi PAK IAKN Tarutung. 4). Tanggapan validator tentang silabus ketiga matakuliah pengembangan tersebut adalah dalam perspektif secara makro, sebab sangat dibutuhkan matakuliah-matakuliah pendidikan lainnya agar harapan tentang keterampilan yang dimaksud dalam penelitian ini dapat dipenuhi sebagaimana yang telah dilaksanakan melalui visi dan misi Prodi Pendidikan Agama Kristen pada sekolah formal.

Pendidikan Agama dan Teologi bermuara kepada pelaksanaan sikap dan perilaku taat pada Tuhan dan perintah-perintah-Nya; bahwa pokok evaluasi bukan pada ranah kognitif (pengetahuan dan pemahaman) dan motorik, tetapi juga mengenai afektif (motivasi seseorang yang mendorongnya untuk setia dan taat) secara berkelanjutan. Oleh situasi berkelanjutan tersebut, kurikulum Prodi Teologi dalam kadar tertentu agaknya membutuhkan pertimbangan tertentu untuk menerima penerapan beberapa prinsip-prinsip umum dan atau utama pendidikan formal, misalnya pada bagian evaluasi. Bukan tidak dapat diukur secara nominal dan ordinal, namun dalam kehidupan umat sendiri secara khusus dalam berteologi, perjalanan hidup keberagamaan dan 
kebertuhanan penuh dengan dinamika yang intens. Akibatnya, hal-hal yang telah diukur tadi dapat berubah sewaktu-waktu sesuai dengan keadaan umat tersebut.

Oleh situasi di atas dan juga oleh saran para validator, tim peneliti merumuskan beberapa saran sehubungan dengan penelitian ini dan atau tindak lanjut yang dapat dilakukan sehubungan dengan pengembangan kurikulum Prodi Teologi ini, yaitu: 1). Agar ketiga matakuliah pengembangan tersebut dapat menciptakan lulusan yang terampil mengajar sebagai bagian integral pemenuhan visi dan misinya, dengan teamteaching, Prodi Teologi IAKN Tarutung sebaiknya tetap menjadi penyelenggaranya. 2). Prodi Teologi IAKN tetap konsisten pada visi dan misinya. Mengenai kebutuhan para lulusannya terampil mengajar, mahasiswa Prodi Teologi dapat mengontrak matakuliahmatakuliah pendidikan pada kolom matakuliah-matakuliah pilihan yang ditawarkan pada Semester IV-VI. 3). Untuk hasil penelitian yang lebih baik dan lebih mendalam, dan mengingat keterbatasan kemampuan peneliti (waktu), maka penelitian ini membutuhkan penelitian lanjutan yang lebih terpadu. Dengan demikian penelitian ini merupakan sebuah usul atau rekomendasi untuk penelitian tindak lanjut. 
Iwan Setiawan Tarigan, Bernhardt Siburian, Arip Surpi Sitompul, Nurelni Limbong, Megawati Manullang

\section{BIBLIOGRAFI}

Hamalik, Oemar. (2006). Manajemen pengembangan kurikulum. Google Scholar

Hamalik, Oemar. (2007). Kurikulum dan Pembelajaran. Jakarta: Bumi Aksara. Google Scholar

Hamzah, Amir. (2019). Metode Penelitian Kualitatif. Malang: CV Literasi Nusantara Abadi. Google Scholar

Ifrianti, Syofnidah. (2018). Membangun Kompetensi Pedagogik Dan Keterampilan Dasar Mengajar Bagi Mahasiswa Melalui Lesson Study. TERAMPIL: Jurnal Pendidikan Dan Pembelajaran Dasar, 5(1), 1-18. Google Scholar

Miller, John P., \& Seller, Wayne. (1985). Curriculum Perspectives and Practice. ERIC. Google Scholar

Pidarta, Made. (1997). Landasan Kependidikan Stimulus Ilmu Pendidikan Bercorak Indonesia. Google Scholar

Sanjaya, Wina. (2008). Kurikulum dan pembelajaran teori dan praktik pengembangan kurikulum tingkat satuan pendidikan (KTSP). Google Scholar

Sugiyono, P. D. (2017). Metode Penelitian Bisnis: Pendekatan Kuantitatif, Kualitatif, Kombinasi, dan R\&D. Penerbit CV. Alfabeta: Bandung. Google Scholar

Sukirman, Dadang. (2010). Keterampilan dasar mengajar. Universitas Pendidikan Indonesia. Google Scholar

Surabaya, Team Didaktik Metodik Kurikulum IKIP. (1989). Pengantar Didaktik Metodik Kurikulum. PBM. Jakarta: Rajawali. Google Scholar

Yulianto, Tunggul, \& Hutasoit, Binsar. (2020). Kesiapan Mengajar Pendidikan Agama Kristen Berdasarkan Kurikulum 2013 pada Mahasiswa Sekolah Tinggi Teologi. REGULA FIDEI: Jurnal Pendidikan Agama Kristen, 5(1), 35-47. Google Scholar

\section{Copyright holder:}

Iwan Setiawan Tarigan, Bernhardt Siburian, Arip Surpi Sitompul, Nurelni Limbong, Megawati Manullang (2021)

First publication right:

Syntax Literate: Jurnal Ilmiah Indonesia

This article is licensed under: 